\title{
Nietzsche, o último filósofo metafísico? (um diálogo acerca da interpretação heideggeriana)
}

\author{
João Evangelista Tude de Melo Neto*,**
}

\begin{abstract}
Resumo: Este artigo possui o propósito de colocar à prova a interpretação heideggeriana acerca das noções nietzschianas de vontade de potência e eterno retorno do mesmo. Para levar a cabo o referido objetivo, de início, apresentaremos o argumento desenvolvido por Heidegger nas suas preleções e textos sobre Nietzsche, editadas e publicadas em dois volumes, no ano de 1961. Num segundo momento, examinaremos, em Nietzsche: sua filosofia dos antagonismos e os antagonismos de sua filosofia, a resposta que Müller-Lauter ofereceu à crítica de Heidegger. Por ocasião deste exame, tentaremos salientar que haveria certa insuficiência na réplica deste comentador. Por fim, iremos recorrer aos textos do próprio Nietzsche para tentar promover uma confrontação com a interpretação do Filósofo da Floresta Negra.

Palavras-chaves: metafísica, Nietzsche, Heidegger, Müller-Lauter, eterno retorno, vontade de potência.
\end{abstract}

\footnotetext{
* Universidade Federal Rural de Pernambuco (UFRPE), Recife, Pernambuco, Brasil.

** Universidade Federal de Pernambuco (UFPE), Recife, Pernambuco, Brasil.

ORCID https://orcid.org/0000-0003-4752-6993

Correio eletrônico: joaonetofilosofia@gmail.com
} 
Melo Neto, J. E. T.

À professora Scarlett Marton

\section{A tese interpretativa de Heidegger}

Na ótica de Andreas Urs Sommer, "já não se pode aprender nada (mais) sobre Nietzsche a partir do Nietzsche de Heidegger". ${ }^{1}$ Para o comentador suíço, a análise interpretativa de Heidegger ao pensamento nietzschiano foi levada a cabo por meio de uma seleção pouco escrupulosa das ideias e dos textos de Nietzsche, visto que a referida análise teria sido realizada a partir dos interesses e à luz da própria filosofia heideggeriana. Ora, entendemos que é justamente tendo a consciência de que os escritos de Heidegger acerca de Nietzsche não podem ser lidos como uma espécie de manual - o qual teria por objetivo fornecer um esclarecimento rigoroso e "objetivo" sobre a filosofia nietzschiana -, que podemos, de fato, aprender algo a mais sobre Nietzsche com Heidegger. Isto é, para aprender com Heidegger, não basta apenas escutar o que ele nos diz explicitamente, mas também devemos buscar o que pode ser ensinado por intermédio de seu silêncio seletivo. Nesse sentido, é, no silêncio de Heidegger, que pretendemos dar a palavra ao próprio Nietzsche e aprender um pouco mais sobre este. Enfim, se formos capazes de promover um diálogo entre os dois filósofos, temos a impressão de que é possível extrair do Nietzsche de Heidegger algo mais do que nele foi dito. Para realizarmos esse diálogo, apresentaremos, de início, o que foi dito pela interpretação heideggeriana para, posteriormente, trazer o que, no nosso entender, pode ser respondido pelo pensamento nietzschiano.

$\mathrm{Na}$ verdade, a abordagem heideggeriana ao pensamento de Nietzsche possui um caráter multifacetado, visto que é possível encontrar, ao longo da obra do filósofo da Floresta Negra, diferentes enfoques interpretativos acerca da filosofia nietzschiana. ${ }^{2}$ Contudo, no

1 A. U. Sommer, 2017. p. 282.

2 A esse respeito, conferir: F. R. de M. Barros, , 2020. p. 52-53.

192 | Cad. Nietzsche, Guarulhos/Porto Seguro, v.42, n.1, p. 191-208, janeiro/abril, 2021. 
Nietzsche, o último filósofo metafísico? (um diálogo acerca da...

nosso entender, uma ideia central parece manter-se constante nessas múltiplas interpretações, a saber, a tese de que a filosofia de Nietzsche está inserida na tradição metafísica. É, portanto, com essa temática que vamos nos confrontar no presente artigo. Para levarmos esse intento a cabo, examinamos os volumes I e II de Nietzsche, obra publicada em 1961 que foi organizada a partir de preleções e pequenos ensaios sobre Nietzsche, realizados por Heidegger, entre os anos de 1936 e 1946. Iremos, contudo, delimitar o nosso enfoque no argumento desenvolvido por Heidegger, quando este autor elenca as doutrinas da vontade de potência e do eterno retorno como temas que fariam da filosofia nietzschiana um pensamento metafísico. Destarte, é necessário termos em mente que não almejamos, neste trabalho, realizar um apanhado geral de todas as facetas da relação entre as obras e os pensamentos dos dois filósofos. O nosso objetivo consiste em - tomando por base a análise heideggeriana sobre a vontade de potência e o eterno retorno -, promover um diálogo entre os dois autores e, por esse intermédio, tentar colocar à prova a supracitada tese de Heidegger.

\section{$* * *$}

No entender de Heidegger, Nietzsche conduziu a tradição metafísica a sua fase de acabamento, mas não a sua superação. Isso porque o pensamento nietzschiano, apesar de constituir-se como essa derradeira etapa da história da metafísica, nela ainda estaria inserido, pois a reflexão do filósofo do martelo também caracterizar-se-ia - nos termos do filósofo da Floresta Negra - como um esquecimento do ser. ${ }^{3}$ $\mathrm{Na}$ ótica de Heidegger, esse esquecimento do ser, no que se refere

\footnotetext{
3 Segundo Heidegger, "na história do pensamento ocidental, o ser do ente" foi "desde o princípio pensado, mas [...] a verdade do ser" teria "permanecido impensada". 0 pensamento ocidental "enquanto metafísica teria encoberto expressamente, ainda que não conscientemente, o acontecimento dessa recusa". Por isso, esclarece o filósofo, "a interpretação que se segue da metafísica de Nietzsche precisa procurar primeiramente pensar a filosofia nietzschiana como metafísica a partir da experiência fundamental citada, isto é, a partir dos traços fundamentais da história da metafísica" (M. Heidegger. 2007. p. 197-198).
} 
à filosofia de Nietzsche, poderia ser evidenciado, por exemplo, nas noções de vontade de potência e de eterno retorno do mesmo, as quais consistiriam num discurso acerca do ente em sua totalidade, mas não do $s e r .{ }^{4}$ Com a vontade de potência, Nietzsche teria proposto uma espécie de essência ou caráter fundamental para a totalidade dos entes: "Para Nietzsche todo ser é um vir-a-ser. Todavia, esse vir-a-ser tem um caráter de ação e de atividade do querer. Em sua essência, porém, a vontade é vontade de [potência]". 5 Enfim, Heidegger conclui que Nietzsche compreenderia a vontade de potência como "o caráter fundamental do ente enquanto tal. Por isso, a essência da vontade de [potência] só pode ser questionada e pensada com vistas ao ente enquanto tal, isto é, metafisicamente" ${ }^{6}$

No entender de Heidegger, esse "ser entificado" e constituído essencialmente como vontade de potência configurar-se-ia, em sua totalidade, como eterno retorno do mesmo: "Com o pensamento do eterno retorno do mesmo, Nietzsche se movimenta no interior da questão o que é o ente na totalidade", 7 pois "o ente na totalidade "é" eterno retorno do mesmo". ${ }^{8}$ Nesse sentido, por meio da doutrina do eterno retorno, Nietzsche teria dado, na verdade, uma explicação sobre a existência do ente em sua totalidade. Em suma, para Heidegger, as

\footnotetext{
4. A teorização das noções nietzschianas da vontade de potência e do eterno retorno se faz presente, de forma mais esclarecedora, nos fragmentos póstumos. É justamente nesses textos que Heidegger julga encontrar a verdadeira filosofia nietzschiana (Cf. M. Heidegger, 2007. p. 10-11). Contudo, a análise que o filósofo da Floresta Negra realiza nesses escritos ficou extremamente comprometida por conta das edições por ele utilizadas. Não é nossa intenção, contudo, dar relevância à falta de rigor de Heidegger quando de sua utilização desse espólio nietzschiano. Acerca dessa questão, o trabalho de Barros já é deveras esclarecedor (Cf. F. R. de M. Barros, 2020. p. 58-63). Conferir, também: A. U. Sommer, 2017, p.273-277.
}

5 M. Heidegger, 2007, p. 9.

6 M. Heidegger, 2007, p. 200.

7 M. Heidegger, 2007, p. 282.

8 M. Heidegger, 2007, p. 361. Ainda sobre a interpretação heideggeriana que considera a doutrina do eterno retorno como um discurso metafísico acerca da totalidade do ente, conferir, na mesma obra, passagens nas páginas 197, 284 e 348.

194 | Cad. Nietzsche, Guarulhos/Porto Seguro, v.42, n.1, p. 191-208, janeiro/abril, 2021. 
Nietzsche, o último filósofo metafísico? (um diálogo acerca da...

duas noções basilares da cosmologia nietzschiana ${ }^{9}$ manifestariam o caráter metafísico da filosofia de Nietzsche, pois elas ainda estariam enredadas num modo de pensar que, durante praticamente toda história do pensamento ocidental, teria "entificado" o ser.

\section{Uma resposta de Müller-Lauter a Heidegger}

Müller-Lauter, em Nietzsche sua filosofia dos antagonismos e os antagonismos de sua filosofia,${ }^{10}$ vai desenvolver um contra-argumento direcionado à interpretação heideggeriana - sobretudo no que diz respeito à compreensão de Heidegger acerca da noção de vontade de potência. Vejamos o que diz o comentador: com "seu discurso da unidade do múltiplo, Nietzsche não visa a uma raiz metafísica, mas a uma relação recíproca: dependência dos múltiplos entre si que se dá no conjunto de um mundo único". ${ }^{11} \mathrm{Ou}$ seja, "toda manifestação de vontade de potência pressupõe uma multiplicidade" ${ }^{" 12}$ e, nesse sentido, a vontade de potência não deveria ser compreendida como unidade absoluta. Enfim, "O múltiplo dos quanta de poder não há, pois, que ser entendido como pluralidade de dados-últimos quantitativamente irredutíveis, não como pluralidade de 'mônadas' indivisíveis". ${ }^{13}$

Na ótica desse comentador, entender o cosmo como um conjunto plural de forças conflitantes significaria, portanto, escapar das teias da metafísica. Isso porque as vontades de potências - ou, se preferirmos,

9 Ao utilizarmos o termo 'cosmologia', tomamos como base o trabalho de Marton (MARTON, S. Nietzsche, das forças cósmicas aos valores humanos. Belo Horizonte: UFMG, 2010).

10 Restringimos nossa análise ao contra-argumento de Müller-Lauter que está presente em Nietzsche: sua filosofia dos antagonismos e os antagonismos de sua filosofia e em A doutrina da vontade de poder em Nietzsche. É necessário ressaltar que o diálogo com o referido comentador cumpre uma meta secundária neste artigo. Objetivo central do presente trabalho é tentar dar conta da questão supracitada no corpo do texto.

11 W. Müller-Lauter, 2009 (sic) [2011], p. 67.

12 W. Müller-Lauter, 2009, p. 68.

13 W. Müller-Lauter, 1997, p. 77.

Cad. Nietzsche, Guarulhos/Porto Seguro, v.42, n.1, p. 191-208, janeiro/abril, 2021. | 195 
as "forças" - não poderiam ser entendidas como unidades substanciais, visto que, no eterno combate que constitui a totalidade cósmica, essas vontades de potências só "existiriam" enquanto um movimento de oposição às vontades de potências rivais. ${ }^{14}$ Consequentemente, elas não poderiam ser concebidas a partir da "rigidez" ontológica do ente. No nosso entender, entretanto, essa argumentação não responde, de forma plenamente satisfatória, à questão de Heidegger, pois a concepção do cosmo como um conjunto de forças plurais e interdependentes ainda estaria inserida no registro heideggeriano de metafísica. Afirmar que o mundo é constituído por um conjunto de forças oponentes diria Heidegger - é entender o caráter geral do mundo como sendo essencialmente um impulso para a luta. Ou seja, a teoria das forças/ vontade de potência seria uma tentativa de responder à pergunta acerca da essência do ente em sua totalidade, uma vez que consistiria numa resposta a partir de uma explicação sobre a constituição última e essencial do cosmo. Enfim, na ótica do Nietzsche de Heidegger, impulso ao domínio e força de oposição -, isto é, vontade de potência - caracterizariam a essência metafísica do ente em seu todo.

Müller-Lauter, no entanto, rebateu um raciocínio análogo ao acima exposto, da seguinte forma: "a vontade de potência é, na verdade, qualidade comum ao que é quantitativamente distinto (conforme potência)" ${ }^{15}$ Contudo, segundo o comentador, não se poderia "reduzir esse traço comum à simplicidade de um princípio fundante: essa qualidade existe somente na pluralidade das diferenças quantitativas". 16 Por esse motivo, "falar de qualidade como se ela existisse 'em si', 'antes' das particularizações quantitativas, significa compreender mal a filosofia de Nietzsche, como se fosse uma metafísica". ${ }^{17}$ Em outros termos, na ótica de Müller-Lauter, só

14 Neste ponto, Michel Haar aproxima-se de Müller-Lauter (Cf. M. Haar, 1993. p. 12).

15 W. Müller-Lauter, 2009, p. 68.

16 W. Müller-Lauter, 2009, p. 68.

17 W. Müller-Lauter, 2009, p. 68.

196 | Cad. Nietzsche, Guarulhos/Porto Seguro, v.42, n.1, p. 191-208, janeiro/abril, 2021. 
Nietzsche, o último filósofo metafísico? (um diálogo acerca da...

há vontade de potência enquanto qualidade comum a todas as forças porque há multiplicidade de forças em conflito, pois a vontade de potência não é algo que subsiste ao embate dessas forças. Apesar de considerarmos a análise do comentador plenamente plausível, entendemos que, talvez, ela acabe por expor um problema inerente à própria teoria das forças/vontade de potência. A esse respeito, caberia, aqui, colocar a seguinte questão: o que impulsionaria essas forças ao combate? A resposta parece óbvia: seu caráter constitutivo como vontade de potência. Ora, isso parece nos lançar, todavia, num raciocínio circular, a saber, a vontade de potência só se expressa enquanto qualidade por intermédio do conflito das múltiplas forças, mas só há conflito porque há um caráter conflitivo que constitui o modo de ser dessas mesmas forças, qual seja, o modo de ser como vontade de potência! Enfim, ao que nos parece, a réplica desenvolvida por Müller-Lauter, em Nietzsche sua filosofia dos antagonismos e os antagonismos de sua filosofia, ainda não foi plenamente suficiente para responder à crítica de Heidegger a Nietzsche.

\section{Passando, mais uma vez, a palavra a Heidegger}

No nosso entender, só podemos compreender, de forma satisfatória, a interpretação de Heidegger ao pensamento nietzschiano, se tivermos em mente como a metafísica é, de fato, entendida no contexto da filosofia heideggeriana. E, para tanto, temos de levar em conta dois temas norteadores de Ser e tempo, quais sejam, as questões da diferença ontológica e do esquecimento do ser pela tradição metafísica. Em outros

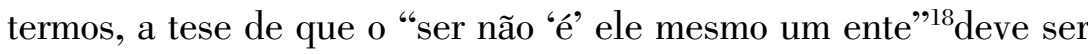
tomada como ideia diretriz para compreendermos a análise do filósofo da Floresta Negra, a qual defende que a filosofia de Nietzsche está inserida na tradição metafísica do esquecimento do ser. Na verdade, é o próprio Heidegger quem nos indica esse caminho quando analisa a suposta

18 M. Heidegger, 2012. p. 43. 
metafísica nietzschiana no segundo volume de Nietzsche. No capítulo VI, intitulado de A Metafísica de Nietzsche, ele afirma: "A tentativa [a de compreender o caráter metafísico da filosofia de Nietzsche] que se segue só pode ser concomitantemente pensada de maneira suficiente a partir da experiência fundamental de Ser e tempo". ${ }^{19}$

Levando em conta a recomendação do filósofo, é preciso lembrar que a noção heideggeriana de metafísica não se restringe, apenas, a uma forma de pensar que promove uma cisão dualista na efetividade. Em outros termos, 'metafísica', em Heidegger, não é sinônimo da velha tese que advoga a separação entre o mundo sensível e o mundo suprassensível. Monismos materialistas e cosmologias que concebem a efetividade como pura imanência, por exemplo, também enquadrarse-iam na acepção de metafísica que o filósofo tem em mente. $\mathrm{Na}$ verdade, Heidegger entende a metafísica como uma investigação - que se esquecendo da verdade do sentido ser - volta-se a uma enquete acerca dos fundamentos últimos do ser do ente. Concebendo o ser, por vezes, como um ente fundamental e, em outras ocasiões, como o fundamento do ente, o modo metafísico de pensar - sempre voltado ao ente - seria responsável pela grande confusão da história da filosofia, isto é, o equívoco da identificação do ser ao ente. Enfim, as respostas oferecidas pela metafísica à questão do ser teriam entificado o ser.

É tendo essa problemática em mente que, em Ser e tempo, Heidegger tenta redirecionar o caminho de sua reflexão ontológica. No seu entender, a pergunta acerca do "sentido ser" deveria se voltar para o próprio ente que coloca essa questão, a saber, o Dasein. ${ }^{20} \mathrm{Ou}$ seja, antes de buscar uma fundamentação "fora" do Dasein - isto é, uma fundamentação (ôntica) em outro ente qualquer que não o Dasein - a ontologia deveria procurar a resposta acerca do ser no

19 M. Heidegger, 2007, p. 197.

20 Neste ponto, estamos próximos da análise de Ernildo Stein: "No início da obra Heidegger situa a questão da ontologia fundamental, do sentido do ser [...] A clarificação desta questão somente pode resultar do recurso ao único ente que compreende ser - o homem (Dasein), o estar-ấ” (E. Stein, 2008, p.13).

198 | Cad. Nietzsche, Guarulhos/Porto Seguro, v.42, n.1, p. 191-208, janeiro/abril, 2021. 
Nietzsche, o último filósofo metafísico? (um diálogo acerca da...

próprio Dasein. ${ }^{21}$ Responder a questão do ser a partir de um "ente fundamental" (seja ele ideal, material, lógico, imanente, transcendente etc.) ou da essência do ente (seja ela imanente, ideal etc.) significaria permanecer no solo ôntico da antiga metafísica e, por consequência, negligenciar a verdadeira ontologia. Isso porque esse procedimento não levaria em conta que o "lugar" a partir do qual é realizada a questão acerca do ser - o Dasein -é, ontologicamente, mais originário do que qualquer outro "lugar" elencado pela tradição metafísica. Em outras palavras, qualquer ente só poderia ser concebido como fundamento metafísico porque ele é concebido, como tal, primordialmente, pelo Dasein: as "ontologias cujo tema é o ente que não possui o caráterde-ser conforme o Dasein estão fundadas e portanto motivadas na estrutura" ${ }^{22}$ do próprio Dasein.

É pensando dessa maneira que, também em Ser e tempo, Heidegger se propõe a realizar sua analítica existenciária, isto é, a análise da estrutura ontológica do Dasein: "se deve buscar na analítica existenciária do Dasein a ontologia-fundamental, da qual somente todas as outras podem surgir". ${ }^{23}$ Dito de outra forma, toda metafísica só teria sido possível até hoje porque a questão do ser do ente foi colocada por um ente específico, o Dasein. E é por essa razão que Heidegger entende que uma verdadeira ontologia deveria começar, justamente, pelo Dasein: "o Dasein se mostrou como o ente que, antes de todo o outro ente, deve ser em primeiro lugar ontologicamente interrogado". ${ }^{24} \mathrm{Ou}$ seja, já que o Dasein é o "lugar" a partir do qual a questão do ser vem à tona, então "uma analítica do Dasein deve, portanto, permanecer a primeira exigência da pergunta pelo ser". ${ }^{25}$

21 Aqui, também estamos próximos a Ernildo Stein: “A ontologia fundamental é apresentada como crítica da ontologia tradicional. ST visa a 'destruição da ontologia do puramente subsistente' de extração greco-cristã-moderna, da ontologia da coisa" (E. Stein, 2008, p.12).

22 M. Heidegger, 2012, p. 63.

23 M. Heidegger, 2012, p. 63.

24 M. Heidegger, 2012, p. 63.

25 M. Heidegger, 2012, p. 73.

Cad. Nietzsche, Guarulhos/Porto Seguro, v.42, n.1, p. 191-208, janeiro/abril, 2021. | 199 
Ao longo de sua analítica existenciária, Heidegger enumera diversos "elementos" estruturais que compõem o arcabouço ontológico do Dasein, a saber, os existenciários - por exemplo: "ser-em", "ser-com", "ser-para-morte", "temporalidade", "corporalidade", "mundidade" etc. No entender de Heidegger, seria a partir desses existenciários que viriam à tona todas as possibilidades ônticas e, portanto, qualquer tipo de tentativa de fundamentação metafísica. Elenquemos, por exemplo, o existenciário mundidade - que é o existenciário que vai mais nos interessar em nossa relação com Nietzsche. Segundo Heidegger, qualquer discurso acerca da totalidade do mundo teria como condição de possibilidade a mundidade - ou "mundo", como, por vezes, Heidegger também se refere à mundidade - que constitui ontologicamente o Dasein. Examinemos como o filósofo descreve este conceito em Ser e tempo:

Mundidade é um conceito ontológico e significa a estrutura de um momento constitutivo do ser-no-mundo [do Dasein]. Mas este, nós o conhecemos como uma determinação existenciária do Dasein. Mundidade é, por conseguinte, ela mesma um existenciário. Quando perguntamos ontologicamente pelo "mundo", de modo algum abandonamos o campo temático da analítica do Dasein. "Mundo" não é ontologicamente uma determinação do ente que em sua essência o Dasein não é, mas um caráter do Dasein ele mesmo. ${ }^{26}$

Destarte, seria a partir da mundidade - elemento constitutivo da estrutura ontológica do Dasein - que toda e qualquer noção ôntica acerca do mundo seria possibilitada. De acordo com esse raciocínio, “a enumeração que se dá ‘dentro’ do mundo: casas, árvores, homens, montes, astros. [...] [é uma] descrição [que] permanece presa ao ente. É ôntica". ${ }^{27} \mathrm{E}$, por isso, não atinge o nível ontológico mais primordial, qual seja, a mundidade. Nesse sentido, qualquer pergunta pretensamente ontológica acerca do ser do mundo que se volta para o

26 M. Heidegger, 2012, p. 200-201.

27 M. Heidegger, 2012, p. 197.

200 | Cad. Nietzsche, Guarulhos/Porto Seguro, v.42, n.1, p. 191-208, janeiro/abril, 2021. 
Nietzsche, o último filósofo metafísico? (um diálogo acerca da...

próprio mundo no intuito de, nele, tentar encontrar uma resposta, não seria, verdadeiramente, uma ontologia radical, pois não diria respeito a essa instância mais fundamental que possibilita qualquer forma de suposta "ontologia" do mundo. Logo, ainda que essa suposta ontologia "conseguisse alcançar a explicação mais pura do ser da natureza em concordância com as proposições fundamentais enunciadas sobre esse ente na ciência matemática da natureza, essa ontologia nunca atingiria o fenômeno do "mundo"' ${ }^{28}$ Em suma, o existenciário mundidade seria mais originário do que qualquer cosmovisão - seja ela cotidiana, científica, religiosa, mística ou filosófica -, pois a munididade seria condição de possibilidade de todas elas.

Levando tudo isso em conta, podemos entender por que, para Heidegger, não seria possível determinar ontologicamente o mundo a partir de um ente que não fosse o próprio Dasein. No mesmo sentido, também percebemos por que, na ótica do filósofo, ficamos impossibilitados de desvelar o ser do mundo, quando adotamos como ponto de partida de nossa enquete o próprio mundo: assim procedendo, continuamos presos a uma interpretação ôntica do mundo. Ora, se levarmos isso em consideração, deveremos concluir que assumir uma concepção cosmológica como fundamento último de toda realidade seria um equívoco metafísico. Isso porque qualquer concepção de mundo estaria enraizada, no final de contas, na estrutura ontológica do Dasein - a qual seria mais originária e fundamental do que qualquer cosmologia. Enfim, o mundo não poderia ser entendido como um ente fundador, visto que o ente "fundador" do cosmo seria o próprio Dasein.

Tendo essa questão em mente, não é surpreendente que Heidegger entenda a cosmologia de Nietzsche - nos referimos, aqui, às doutrinas da vontade de potência e do eterno retorno - como uma teoria metafísica. Neste caso, uma espécie de metafísica que aproximaria o pensamento nietzschiano ao modo de filosofar dos présocráticos, visto que a cosmologia de Nietzsche teria resgatando, em

28 M. Heidegger, 2012, p. 199.

Cad. Nietzsche, Guarulhos/Porto Seguro, v.42, n.1, p. 191-208, janeiro/abril, 2021. | 201 
pleno século XIX, a questão fundamental acerca da arché. É pensando desta forma que, no volume I de Nietzsche, Heidegger vai afirmar que a "metafísica [...] sempre diz respeito [...] aos respectivos conceitos fundamentais de uma filosofia". ${ }^{29} \mathrm{E}$, ainda, que, na busca por esses conceitos fundamentais, a filosofia, em seus primórdios, colocou a "pergunta pela $\alpha \rho \chi \eta ́$ [arché]". ${ }^{30}$ Esse questionamento pela arché seria, entretanto, uma pergunta sobre o princípio $^{31}$ da totalidade do ente:

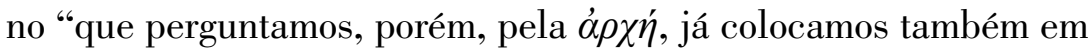
questão todo ente como um todo na totalidade". ${ }^{32}$ Ora, perguntar pela totalidade do ente seria permanecer na pergunta diretriz da metafísica: "o que é há muito perguntado, o que continua agora e continuará sendo perguntado é - o que é o ente?". ${ }^{33}$ Ou seja, "na medida em que

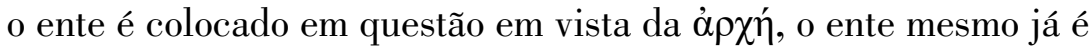
determinado". ${ }^{34}$ Em suma: 1) no entender de Heidegger, o "questionar sobre a $\dot{\alpha} \rho \chi \eta ́ \eta$ [...] é metafísica";35 2) a filosofia nietzschiana ainda

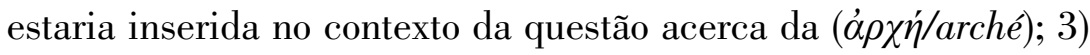
Logo, a filosofia nietzschiana seria metafísica.

Levando em consideração tudo o que dissemos, podemos afirmar que, no entender de Heidegger, tentar encontrar a resposta para a questão "o que é o ente?", buscando pelo princípio fundador ( $\dot{\alpha} \rho \chi \eta$ / arché) deste ente em um ente que não é o Dasein - seja esse ente entendido "como $\varphi v ́ \sigma ı \varsigma$ [physis], seja como criação de um criador, seja como realidade de um espírito absoluto"36 - seria fazer "ontologia"

29 M. Heidegger, 2007, p. 350.

30 M. Heidegger, 2007, p. 351.

31 Heidegger entende arché como princípio: “Traduzimos essa palavra por "princípio”" (M. Heidegger, 2007, p. 351).

32 M. Heidegger, 2007, p. 352.

33 M. Heidegger, 2007, p. 352.

34 M. Heidegger, 2007, p. 353.

35 M. Heidegger, 2007 p. 354.

36 Ibidem. p. 354.

202 | Cad. Nietzsche, Guarulhos/Porto Seguro, v.42, n.1, p. 191-208, janeiro/abril, 2021. 
Nietzsche, o último filósofo metafísico? (um diálogo acerca da...

nos moldes da metafísica. Isso porque, aqui, estar-se-ia ignorando que uma ontologia mais fundamental deveria se voltar para o Dasein. Enfim, toda pretensão ontológica de todas as cosmologias ocidentais - incluindo a cosmologia de Nietzsche - enquadrar-se-ia no conceito heideggeriano de metafísica e, assim sendo, o filósofo do martelo teria respondido às mesmas questões que vêm sido colocadas pela metafísica, quais sejam: o que é o ente? qual é o fundamento do ente?

\section{Invertendo a "árvore" de Descartes}

Neste ponto, uma questão se impõe: será que devemos, realmente, compreender a cosmologia nietzschiana como uma tentativa de fundar o ente? Vejamos. Na verdade, entendemos que o pensamento nietzschiano inverte a ordem e a hierarquia habituais das disciplinas filosóficas. ${ }^{37}$ Ora, esteve presente durante parte considerável da história da Filosofia a ideia de que a moral deveria ser fundamentada e derivada de princípios metafísicos - fossem estes transcendentes ou imanentes. Seria, por exemplo, a contemplação da ideia transcendente de Bem que possibilitaria, em Platão, a fundamentação da moral. No período helenístico, são as físicas estoica e epicurista que - enquanto tentativa de fundamentação imanente - ofereceriam sustentação às suas respectivas éticas. Grosso modo, na filosofia medieval do Ocidente, é Deus que constitui a principal base metafísica da moral. No início da modernidade, Descartes irá "deduzir" a res cogitans e a res infinita para elencá-las como princípios metafísicos que garantiriam o verdadeiro e seguro conhecimento científico, o qual, por sua vez, possibilitaria, num momento futuro, a construção de uma moral definitiva..$^{38}$

37 A partir deste ponto, iremos desenvolver um argumento que já havíamos, em certo sentido, iniciado em J. E. T. de Melo Neto, 2020. p. 91-94.

38 Cf. R. Descartes, 2010. p. 591.

Cad. Nietzsche, Guarulhos/Porto Seguro, v.42, n.1, p. 191-208, janeiro/abril, 2021.| 203 
Aliás, é o próprio Descartes que nos oferece contornos metódicos a essa hierarquia de "disciplinas filosóficas" que, como salientamos, pode ser verificada em uma parcela considerável da tradição metafísica. Na célebre passagem na qual compara o saber filosófico a uma árvore, a moral surge como o último dos galhos dessa árvore, a qual possui, como raízes, a metafísica. Em outros termos, a moral filosófica - que deveria tornar-se, futuramente, a moral definitiva - consistiria no derradeiro fruto de um saber filosófico acerca "das primeiras causas, quer dizer, dos princípios". ${ }^{39} \mathrm{~A}$ partir desses princípios é que poderíamos derivar e "regular nossos costumes e nos conduzir nesta vida". ${ }^{40}$ Examinemos a metáfora cartesiana:

Toda a filosofia é como uma árvore, da qual as raízes são a metafísica, o tronco é a física, e os galhos que saem do tronco são todas as outras ciências, que se resumem a três principais, a saber, a medicina, a mecânica e a moral; eu entendo que a mais alta e a mais perfeita moral [-] que pressupondo um inteiro conhecimento das outras ciências [-] é o último grau da sabedoria. ${ }^{41}$

É muito relevante atentar que, na seção 6 de Além de bem e $m a l,{ }^{42}$ Nietzsche parece sustentar um posicionamento inverso em relação a essa tradição fundacionista da metafísica! ${ }^{43}$ Com efeito, aparentemente, ele coloca a analogia de Descartes "de cabeça para baixo". Examinemos o trecho:

39 R. Descartes, R., 2010a, p. 770.

40 R. Descartes, R., 2010a, p. 771.

41 R. Descartes, 2010a, p. 779 e 780 (grifo nosso).

42 É curioso que, segundo Andreas Urs Sommer, a primeira referência a Nietzsche no corpus heideggeriano teria sido realizada, justamente, a partir deste trecho de Além de bem e mal. A ocorrência em questão está na tese de livre docência de Heidegger acerca de Duns Scotus (C.f. A. U. Sommer, A. U. 2017, p. 269).

43 Scarlett Marton já havia chamado atenção sobre a relação entre a Lettre-préface de l'Édition Française des Principes e a seção 6 de Além de bem e mal (Cf. S. Marton, 2001. p. 165).

204 | Cad. Nietzsche, Guarulhos/Porto Seguro, v.42, n.1, p. 191-208, janeiro/abril, 2021. 
Nietzsche, o último filósofo metafísico? (um diálogo acerca da...

se tornou claro que as intenções morais (ou imorais) de toda filosofia constituíram sempre o germe a partir do qual cresceu a planta inteira. De fato, para explicar como surgiram as mais remotas afirmações metafísicas de um filósofo é bom (e sábio) se perguntar antes de tudo: a que moral isto (ele) quer chegar? (JGB/BM, 6 KSA 5.19-20, grifo nosso).

Se realmente levarmos em conta a hipótese de Nietzsche, teríamos de inverter a árvore de Descartes, visto que, na versão do filósofo alemão, a moral não aparece como sendo sustentada por raízes metafísicas. Ao contrário, são as “intenções morais (ou imorais)" que figuram como a semente a partir da qual a árvore de todo "saber" filosófico abrolharia. Consequentemente, nesse contexto, as noções metafísicas - também incluímos, aqui, as $\operatorname{cosmologias}^{44}$ - não deveriam mais ser entendidas como fundamentos dos quais a moral emanaria. Pelo contrário, essas noções supostamente metafísicas reduzir-se-iam a afirmações humanas que teriam brotado de interesses morais preexistentes. Ora, ao admitirmos o modo de pensar de Nietzsche, teremos de entender que a "metafísica" perderia seu caráter de fundamentação ontológica. Isso porque as suas "categorias fundamentais" deixariam de ser propriamente metafísicas - ou seja, não poderiam ser entendidas no sentido tradicional, isto é, como fundamento primeiro - para serem reduzidas a elementos retóricos que, hipostasiados, serviriam para defender uma moral à qual se "quer chegar". ${ }^{45}$ Dito de outra forma, no contexto da hipótese nietzschiana, a "metafísica" deixa de ser metafísica, para se tornar uma ferramenta

44 Em Além de bem e mal 9, por exemplo, o filósofo parece ir numa direção análoga à seção 6, uma vez que também parece entender a cosmologia estoica como uma tentativa de suposta fundamentação metafísica que, na verdade, derivaria de interesses morais preexistentes (Cf. JGB/BM, 9 KSA 5.21-22).

45 Já em Aurora, Nietzsche defendia um posicionamento análogo, quando sustentara que Kant teria criado sua epistemologia a partir de um interesse moral: "a fim de criar espaço para seu 'reino moral', ele viu-se obrigado a estabelecer um mundo indemonstrável, um 'Além' lógico - para isso necessitava de uma critica da razão pura! Em outras palavras: não teria necessitado dela, se para ele uma coisa não fosse mais importante que tudo, tornar o 'mundo moral' inatacável ou, melhor ainda, inapreensível pela razão” (M/A, Prólogo 3 KSA 3.12-15).

Cad. Nietzsche, Guarulhos/Porto Seguro, v.42, n.1, p. 191-208, janeiro/abril, 2021. | 205 
Melo Neto, J. E. T.

de implementação ou de justificação de um determinado conjunto de valores morais.

\section{A cosmologia nietzschiana: uma metafísica da imanência ou uma ferramenta retórica a serviço da implementação do projeto transvalorativo?}

Ora, se reorientarmos a hipótese de Nietzsche em direção da própria filosofia de Nietzsche, então parece que estaríamos autorizados a concluir que a noção da vontade de potência e a doutrina do eterno retorno do mesmo estariam subordinadas aos interesses "morais (ou imorais)" do próprio Nietzsche! Nesses termos, a cosmologia nietzschiana não caracterizar-se-ia como uma investigação metafísica acerca de fundamentos últimos do Universo, mas sim como uma espécie de discurso retórico que teria por meta legitimar o projeto de transvaloração dos valores. Nesse sentido, defendemos a tese de que Nietzsche só elaborou a cosmologia agônica da vontade de potência e a teoria cíclica do eterno retorno porque ele tinha em mente realizar uma transformação radical nos valores ocidentais. Portanto, a argumentação "científico-cosmológica" elaborada pelo filósofo possuiria a importante função de persuadir o homem cientificista do século XIX a redirecionar a sua forma de valorar. Ou seja, a cosmologia da pura imanência proposta por Nietzsche consistiria numa "estratégia" para promover a atitude de afirmação da vida terrena numa civilização dominada pela mentalidade do cientificismo, mas que ainda norteava-se moralmente pela ideia de transcendência.$^{46}$ Destarte, o objetivo último da cosmologia nietzschiana não seria propriamente ontológico, mas valorativo. Enfim, o discurso filosófico de Nietzsche acerca do mundo não visaria desvelar o fundamento

46 Neste ponto, estamos próximos do posicionamento de Patrick Wotling: cf. 2008. p. 418-420; 1995. p. 368-370). 
Nietzsche, o último filósofo metafísico? (um diálogo acerca da...

do ente em sua totalidade, mas transvalorar a relação valorativa do homem ocidental com a imanência.

\section{Nietzsche, the last metaphysical philosopher? (a dialogue about Heidegger's interpretation)}

Abstract: This article has the purpose to challenge the Heideggerian interpretation of Nietzsche's notions of will to power and eternal recurrence. To carry out this objective, we will first present the argument developed by Heidegger in his lectures and texts on Nietzsche, edited and published in two volumes, in 1961. In a second moment, we will examine, in Nietzsche: his philosophy of antagonisms and the antagonisms of his philosophy, the answer that Müller-Lauter offered to Heidegger's criticism. On the occasion of this examination, we will try to point out that there would be a certain insufficiency in this commenter's reply. Finally, we will resort to Nietzsche's own texts to try to promote a confrontation with the Black Forest Philosopher's interpretation.

Keywords: metaphysics, Nietzsche, Heidegger, Müller-Lauter, eternal recurrence, will to power.

\section{Referências}

BARROS, F. R. de M. Nietzsche sob Heidegger. In: AZEREDO, V. D.; FREZZATTI JR, W. A. (org.) Nietzsche e seus intérpretes. Curitiba: CRV, 2020.

DESCARTES, R. Discours de la méthode. In: Oeuvres philosophiques. Tome I. 1618-1637. Paris: Éditions Classiques Garnier, 2010.

. Lettre-préface de l'Édition Française des Principes. In: . Oeuvres philosophiques. Tome III. 1643-1650. Paris: Éditions Classiques Garnier, 2010a.

HAAR, M. Nietzsche et la métaphysique. Paris: Gallimard, 1993.

HEIDEGGER, M. Ser e tempo. Trad. Fausto Castilho. Campinas: Editora Unicamp; Petrópolis: Vozes, 2012. 
Melo Neto, J. E. T.

. Nietzsche I e II. Trad. Marco Antônio Casanova. Rio de Janeiro: Forense Universitária, 2007.

MARTON, S. Nietzsche, das forças cósmicas aos valores humanos. Belo Horizonte: UFMG, 2010.

. Nietzsche e Descartes: Filosofia de epitáfio. In: Extravagâncias: ensaios sobre a Filosofia de Nietzsche. São Paulo: Discurso editorial e Editora Unijuí, 2001.

MELO NETO, J. E. T. Nietzsche à luz dos Antigos: a cosmologia. São Paulo: Editora Unifesp; GEN, 2020.

MÜLLER-LAUTER, W. A doutrina da vontade de poder em Nietzsche. Trad. Oswaldo Giacoia Júnior. São Paulo: Anablume, 1997.

. Nietzsche: sua filosofia dos antagonismos e os antagonismos de sua filosofia.Trad. Clademir Aaraldi. São Paulo: Unifesp, 2009 (sic) [2011].

NIETZSCHE, F. Sämtliche Werke. Kritische Studienausgabe (KSA). Giorgio Colli e Mazzimo Montinari. Berlim: Walter de Gruyter \& Co, 12 ed. 2012, 15 v.

. Aurora. Trad. Paulo César de Sousa. São Paulo: Companhia das Letras, 2004 .

. Além do Bem e do Mal. Trad. Paulo César de Sousa. São Paulo: Companhia das Letras, 2005.

SOMMER, A. U. Nietzsche como placa giratória "na" modernidade? O Nietzsche de Heidegger nos Cadernos negros e o papel do filósofo. In: NASSER, E.; RUBIRA, L. (org.) Nietzsche no século XXI. Porto Alegre: Zouk, 2017.

STEIN, E. Seis estudos sobre 'Ser e tempo’. Petrópolis: Vozes, 2008.

WOTLING, P. Nietzsche et le problème de la civilisation. Paris: Presses Universitaires de France, 1995. . La philosophie de l'esprit libre. Paris: Flammarion, 2008.

Enviado 07/11/2020

Aceito: $14 / 12 / 2020$

208 | Cad. Nietzsche, Guarulhos/Porto Seguro, v.42, n.1, p. 191-208, janeiro/abril, 2021. 